\title{
Oficina de memória para idosos: espaço para conhecimento, socialização e ludicidade
}

\author{
Cecília Souza Oliveira*, Sylvio Rogério Costa**, Ingrid Cristina Santos ${ }^{* * *}$, Carlos Eugênio Lemos ${ }^{* * * *}$
}

\section{Resumo}

Cada etapa da vida do indivíduo deve ser compreendida e vivenciada conforme suas particularidades e considerada com base em uma gama de vertentes pessoais, sociais e cognitivas próprias. Como forma de proporcionar aos idosos um conhecimento mais amplo do envelhecimento normal e da demência, têm sido realizadas oficinas para essa população. Este estudo compreende a análise, desenvolvida com auxílio de questionários, entrevistas e relatos, de três momentos distintos (início, meio e fim) de uma oficina de memória para idosos realizada ao longo de 2011. No início do projeto, procedeu-se a uma entrevista semiestruturada envolvendo temáticas relacionadas a hábitos de vida e aspectos cognitivos. No final do primeiro semestre de 2011, realizou-se o segundo momento, que consistiu na construção de uma autobiografia, de forma que, pela evocação, pudessem ser estimuladas as lembranças consideradas mais remotas para serem expressas num livro de memórias. Após um ano de realização da oficina, aplicou-se aos participantes uma nova entrevista se- miestruturada, com o intuito de verificar se o trabalho foi útil para esclarecer a respeito do processo de envelhecimento e das mudanças cognitivas, especialmente da memória. A finalidade primordial da oficina de memória foi pautar-se em três pilares, conhecimento, socialização e ludicidade, visando, ainda, a representar um projeto de extensão no sentido mais amplo da palavra, ou seja, objetivando que os participantes adquirissem os conhecimentos relativos aos processos da memória e das particularidades da terceira idade para atuar como agentes multiplicadores do conhecimento adquirido.

Palavras-chave: Memória. Idosos. Socialização. Lúdico.

* Doutora em Neurociências. Docente da Universidade Federal Fluminense - Polo Campos dos Goytacazes. Endereço para correspondência: Rua José do Patrocínio, 71, Centro, CEP: 28010-385, Campos dos Goytacazes - RJ. E-mail: ceci_souzaoliveira@yahoo.com.br.

*** Mestre em Gerontologia.

**** Mestra em Psicologia Social. Pós-graduada em Terapia Familiar.

**** Doutor em Sociologia e Antropologia. Docente da Universidade Federal Fluminense - Polo Campos dos Goytacazes.

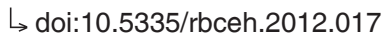




\section{Introdução}

Cada etapa da vida do indivíduo deve ser compreendida e vivenciada conforme suas particularidades e considerada com base em uma gama de vertentes pessoais, sociais e cognitivas próprias. Contudo, de forma geral, do ponto de vista cognitivo, o envelhecimento normal é caracterizado por deficit na memória episódica verbal e prejuízo nas funções executivas, bem como pela diminuição na velocidade de processamento de informações. (HAMDAM; BUENO, 2005). Segundo Mendes et al. (2005), o papel social do idoso será resultado da conjugação de dois principais fatores: a maneira pela qual a sua história de vida foi estabelecida e as condições em que ele se encontra no atual momento para suas realizações pessoais.

Os autores destacam, ainda, a aposentadoria como um marco relevante na vida da pessoa, revelando-se, muitas vezes, dotada de uma função dupla e até mesmo antagônica, pois, ao mesmo tempo em que pode oportunizar descanso e lazer, pode significar um rompimento com aquilo que a representava como indivíduo produtivo na sociedade. Outro aspecto recorrente na literatura relativa à terceira idade, é o sentimento de solidão, resultado do isolamento social, em razão de limitações físicas e orgânicas, redução do número de atividades realizadas fora do ambiente doméstico ou mesmo devido à perda das pessoas com idades semelhantes que faziam parte de seu convívio. (GARRIDO; MENEZES, 2002;
SILVA; CARVALHO; SANTOS, 2007; GUERRA; CALDAS, 2010). Ressalta-se que as vertentes pessoais, sociais e cognitivas estão intrinsecamente ligadas, de modo que o prejuízo numa dessas áreas poderá afetar as demais; por exemplo, a perda significativa na memória resultante de algum processo demencial poderá ocasionar, também, um maior aumento das restrições sociais e pessoais desse idoso. (SOARES et al., 2010).

Se, por um lado, há mais de duas décadas discute-se no meio científico o aumento da população idosa brasileira e mundial (KALACHE; VERAS; RAMOS, 1987; FELICIANO; MORAES; FREITAS, 2004), por outro, verifica-se a persistência de um grande desconhecimento sobre as especificidades dessa fase da vida, particularmente no que tange a diferenciar o que seriam características normais do envelhecimento e o que poderia caracterizar o processo demencial. É importante salientar que, apesar de no envelhecimento normal ocorrerem prejuízos na memória, nas funções executivas e na velocidade de processamento das informações, esses deficit não são suficientes para interferir de maneira significativa na manutenção das atividades de vida diária e das atividades de vida prática do idoso. Contudo, observa-se que, muitas vezes, o desconhecimento dessas características típicas pode levar a que o idoso comece a acreditar que está acometido por uma demência, angustiando-se muito com esse fato. (PINTO et al., 1999). 
Na demência, há um comprometimento progressivo da memória associado a prejuízos crescentes quanto à capacidade de resolução de problemas, de orientação, de linguagem, de atenção e de habilidades para realizar as atividades de vida diária. (LUZARDO; GORINI; SILVA, 2006). Nesse sentido, cabe destacar que, na demência, os prejuízos cognitivos, além de serem mais severos do que os apresentados no envelhecimento normal e de afetarem, necessariamente, mais de uma função cognitiva, revelam-se progressivos e comprometem significativamente a independência do indivíduo.

Como forma de proporcionar aos idosos um conhecimento mais amplo acerca do envelhecimento normal e da demência, têm sido realizadas oficinas para essa população. (ARRUDA, 2010). Uma dessas experiências foi descrita por Almeida et al. (2007), o qual realizou dez encontros com 45 idosos, abordando temas referentes a memória, estilos de vida, bem como estratégias cognitivas para melhor enfrentar os prejuízos mnésticos, caso ocorressem. Os autores identificaram que a oficina foi útil para oferecer maior conhecimento acerca dos temas relativos à terceira idade e, a partir disso, possibilitar um melhor enfrentamento das situações diárias. Além desse aspecto, observaram que a oficina possibilitou um aumento da socialização e da estimulação mútua entre os integrantes.

Foi realizada por Souza e Chaves (2005) uma experiência semelhante, desenvolvida ao longo de oito reuniões com um grupo de idosos saudáveis, envolven- do apresentação de palestras, aplicação de jogos e atividades, de maneira geral, que estimulassem o raciocínio e a resolução de problemas. Por meio da aplicação do teste do Miniexame do Estado Mental (MEEM) antes e após a realização da oficina, os autores concluíram que houve melhora significativa no seu desempenho. Nosso estudo propôs-se a analisar, com auxílio de questionários, entrevistas e relatos, três momentos distintos (início, meio e fim) de uma oficina de memória para idosos realizada ao longo de 2011.

\section{Método}

Este trabalho foi aprovado pelo Comitê de Ética em Pesquisa da Universidade Federal Fluminense - Polo Campos dos Goytacazes, de acordo com o processo $\mathrm{n}^{\circ}$ 001/2012. Na condição de uma oficina de memória, a proposta foi utilizar estratégias que permitissem o registro das experiências vivenciadas pelos alunos em sua participação nas atividades realizadas. A estimulação cognitiva, a busca de uma maior autonomia e a sociabilidade constituíram os eixos que nortearam a organização, a execução e a avaliação contínua do trabalho. Numa perspectiva interdisciplinar, foi cumprida uma carga horária anual de 96 horas, sendo 3 horas semanais na oficina e 1 hora em atividades extracurriculares. Partindo de uma perspectiva autobiográfica da memória e considerando-a como um processo, não como um fim, o projeto foi desenvolvido entre os meses de abril e novembro de 2011, na sede do PUCG/UFF, às terças e quintas-feiras, das $9 \mathrm{~h}$ às $10 \mathrm{~h} 30 \mathrm{~min}$. 
A equipe organizadora e executora foi composta por cinco profissionais das áreas de psicologia, gerontologia, biologia e sociologia, contando, também, com a participação de três alunos do curso de Serviço Social, que receberam bolsas de treinamento, financiadas pelo Programa de Graduação (Prograd) da UFF. Os participantes idosos foram selecionados no início do ano a partir de uma lista com sessenta pré-inscritos. Os critérios estabelecidos para a entrada foram: interesse dos candidatos, preferência para os de mais idade, indicação médica, ter frequentado a turma anual do Programa da Universidade para a Terceira Idade desenvolvido no PUCG/UFF. Foram escolhidas 16 pessoas com idade entre 60 e 85 anos. Optou-se por trabalhar com um grupo menor, tendo em vista as diferenças cognitivas e a necessidade de um acompanhamento personalizado.

No início do projeto, realizou-se uma entrevista semiestruturada com as temáticas descritas na Figura 1 e aplicou-se o MEEM a cada um dos ingressantes.

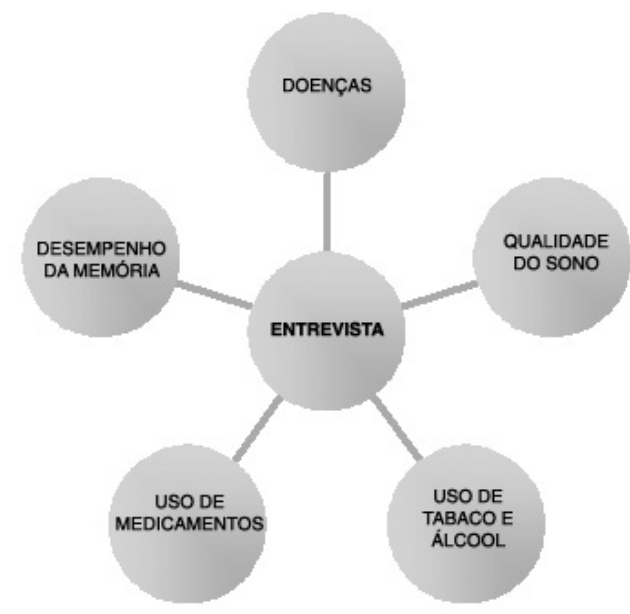

Figura 1 - Tópicos retratados em entrevista no início do projeto.
No final do primeiro semestre, foi realizada uma segunda avaliação, na qual, por meio de um texto escrito, os idosos deveriam expressar o seu nível de satisfação com as atividades realizadas até aquele momento. No final do projeto, procedeu-se a uma avaliação pautada num questionário composto de dez perguntas, conforme o quadro abaixo:

\section{Questionário}

1) se começou a realizar alguma atividade doméstica que não era feita anteriormente à participação na oficina de memória

2) como ele poderia explicar para um amigo a doença de Alzheimer

3) o que sente ou o que pensa atualmente quando se esquece de algo

4) se é capaz de realizar as tarefas do dia a dia

5) se consegue apanhar ônibus, pagar contas, ir ao supermercado, ir à padaria, contratar serviços ou sair para passear sozinho

6) como considera a própria memória ao compará-la com a de pessoas da mesma idade

7) se existe alguma tarefa que gostaria de executar, mas não consegue mais por causa da memória

8) se a oficina mudou alguma coisa no seu conhecimento sobre memória

9) quais as dicas que daria a um amigo para melhorar a memória

10) se na sua família há alguma pessoa com prejuízo na memória

A proposta do projeto foi dividir cada encontro da oficina de memória em três momentos, conforme é relatado a seguir. 


\section{Primeiro momento}

Esse momento foi reservado à socialização de informações relevantes sobre a memória do ponto de vista da educação em neurociência, pautadas em bibliografia específica, com preocupação especial em transmitir o conteúdo de maneira adequada para a idade e a escolaridade dos participantes envolvidos (SCHACTER, 2003; IZQUIERDO, 2004; LENT, 2008). Para tanto, foram apresentados vídeos, abordando assuntos como funcionamento do cérebro, alimentação, patologias, exercício físico, informações educativas de neurociência, entre outros.

\section{Segundo momento}

Nesse momento, trabalhou-se com a memória declarativa episódica. Para tanto, optou-se por utilizar como eixo a construção de uma autobiografia, de forma que, pela via da evocação, as lembranças consideradas mais remotas pudessem ser estimuladas e expressas num livro de memória (textos, colagens, desenhos). Assim, a infância foi o eixo sobre o qual se estruturou a abordagem de cada uma das atividades pensadas para esse momento do curso, tais como: a casa em que se viveu, as brincadeiras e as cantigas, a família de origem, a vizinhança, a escola, as festas, a alimentação, os sonhos, entre outras.

\section{Terceiro momento}

No terceiro momento, voltado para o estímulo ao desempenho da memória operacional ou de trabalho, utilizou-se duas estratégias. A primeira constituiu-se de dois cadernos de atividades, o de sala de aula, tendo vários exercícios de incentivo cognitivo a serem realizados no encontro, e o de casa, destinado a anotações descrevendo a rotina do dia a dia. A segunda estratégia estava baseada nos jogos de natureza cognitiva e de promoção da sociabilidade, como o dominó, a batalha naval, dama, resta um, de formação de palavras e muitos outros.

\section{Resultados e discussão}

\section{Primeiro momento}

Os dados obtidos por meio do questionário estão descritos na Tabela 1. 
Tabela 1 - Dados referentes ao questionário aplicado aos idosos no primeiro momento da oficina de memória.

\begin{tabular}{|c|c|c|c|}
\hline Idade (M, DP) & $68,38(11,83)$ & $\begin{array}{l}\text { Utilizam medicação } \\
\text { Sim } \\
\text { Não }\end{array}$ & $\begin{array}{l}13 \\
00\end{array}$ \\
\hline $\begin{array}{l}\text { Escolaridade } \\
\text { Ensino fundamental } \\
\text { Ensino médio } \\
\text { Ensino superior }\end{array}$ & $\begin{array}{l}03 \\
09 \\
01\end{array}$ & $\begin{array}{l}\text { Fuma } \\
\text { Muito } \\
\text { Pouco } \\
\text { Às vezes } \\
\text { Nunca }\end{array}$ & $\begin{array}{l}00 \\
00 \\
01 \\
12\end{array}$ \\
\hline $\begin{array}{l}\text { Dorme bem } \\
\text { Sim } \\
\text { Não }\end{array}$ & $\begin{array}{l}12 \\
01\end{array}$ & $\begin{array}{l}\text { Bebe } \\
\text { Muito } \\
\text { Pouco } \\
\text { Às vezes } \\
\text { Nunca }\end{array}$ & $\begin{array}{l}00 \\
00 \\
01 \\
12\end{array}$ \\
\hline $\begin{array}{l}\text { Utilização de medicamento para } \\
\text { dormir } \\
\text { Sim } \\
\text { Não }\end{array}$ & $\begin{array}{l}07 \\
06\end{array}$ & $\begin{array}{l}\text { Televisão } \\
\text { Muito } \\
\text { Pouco } \\
\text { Às vezes } \\
\text { Nunca } \\
\end{array}$ & $\begin{array}{l}04 \\
02 \\
07 \\
00\end{array}$ \\
\hline $\begin{array}{l}\text { Concentração } \\
\text { Ótima } \\
\text { Boa } \\
\text { Regular } \\
\text { Ruim } \\
\end{array}$ & $\begin{array}{l}01 \\
03 \\
09 \\
00\end{array}$ & $\begin{array}{l}\text { Rádio } \\
\text { Muito } \\
\text { Pouco } \\
\text { Às vezes } \\
\text { Nunca }\end{array}$ & $\begin{array}{l}05 \\
04 \\
00 \\
04\end{array}$ \\
\hline $\begin{array}{l}\text { Memória } \\
\text { Ótima } \\
\text { Boa } \\
\text { Regular } \\
\text { Ruim } \\
\end{array}$ & $\begin{array}{l}01 \\
03 \\
09 \\
00\end{array}$ & $\begin{array}{l}\text { Leitura } \\
\text { Muito } \\
\text { Pouco } \\
\text { Às vezes } \\
\text { Nunca } \\
\end{array}$ & $\begin{array}{l}03 \\
06 \\
03 \\
01\end{array}$ \\
\hline $\begin{array}{l}\text { Nota para a memória de } 0 \text { a } 10 \\
(\mathrm{M}, \mathrm{DP})\end{array}$ & $6,8(1,9)$ & $\begin{array}{l}\text { Utilizam computador } \\
\text { Muito } \\
\text { Pouco } \\
\text { Às vezes } \\
\text { Nunca }\end{array}$ & $\begin{array}{l}01 \\
02 \\
02 \\
08\end{array}$ \\
\hline $\begin{array}{l}\text { Problemas de saúde } \\
\text { Osteoporose } \\
\text { Artrite } \\
\text { Labirintite } \\
\text { Hipertensão } \\
\text { Diabetes } \\
\text { Depressão } \\
\text { Coluna } \\
\text { Problemas com a tireoide } \\
\text { Síndrome do pânico } \\
\text { Outros }\end{array}$ & $\begin{array}{l}06 \\
02 \\
02 \\
09 \\
02 \\
03 \\
08 \\
00 \\
04 \\
05\end{array}$ & $\begin{array}{l}\text { Utilizam internet } \\
\text { Muito } \\
\text { Pouco } \\
\text { Às vezes } \\
\text { Nunca }\end{array}$ & $\begin{array}{l}01 \\
01 \\
02 \\
08\end{array}$ \\
\hline
\end{tabular}


No início da oficina de memória, as informações dos questionários indicaram o perfil dos participantes, bem como os seus hábitos de vida. Com relação à escolaridade, observou-se que $69 \%$ dos idosos estudaram até o nível médio e um deles realizou curso superior. Dados referentes ao grau educacional têm sido correlacionados com variáveis distintas em diversos estudos, apontando que o número de anos que determinada pessoa frequentou a escola pode revelar aspectos referentes ao seu perfil social e aos seus hábitos.

Lima-Costa (2004) concluiu em seu estudo que, quanto menor era a escolaridade dos idosos, maior era o sedentarismo, além de terem uma alimentação menos saudável, ao passo que, quanto maior a escolaridade, menores foram as taxas de exposição a alguns fatores de risco como bebida e cigarro. Esses dados corroboram os achados do nosso estudo, que indicaram que $92 \%$ dos idosos não consomem bebida alcoólica e não fumam. Parahyba et al. (2005) discutiram a relação entre a incapacidade funcional e algumas variáveis demográficas em um grupo de idosos. A partir da definição de incapacidade funcional como uma dificuldade para realizar atividades típicas e padronizadas, os autores identificaram que, quanto maior a incapacidade funcional, maior a idade e menor a escolaridade dos idosos.

Com relação aos hábitos do sono, verificou-se que, apesar de $92 \%$ dos idosos relatarem dormir bem, $54 \%$ admitiram que utilizam medicação para esse fim, ou seja, conseguem ter uma noite satisfatória de sono somente com o uso de medicações específicas para induzi-lo. Diferentes estudos (GEIB et al., 2003; SOUZA; REIMÃO, 2004) cada vez mais têm destacado a importância do sono não apenas como um meio de restaurar física e psicologicamente o ser humano, mas também como um momento no qual inúmeros processos biológicos ocorrem, a saber: retenção da memória, manutenção de uma boa pressão arterial e do humor dos indivíduos. Mesmo o envelhecimento normal é caracterizado por modificações na quantidade e na qualidade do sono, atingindo mais da metade dessa população. Isso decorre de inúmeros fatores emocionais, físicos, ambientais ou da própria mudança nos padrões de sono. (SOUZA; REIMÃO, 2004). Nesse sentido, a simples orientação dos idosos a respeito dessas transformações, típicas da fase em que se encontram, poderia ser útil para lidarem com tais questões mais naturalmente e, em muitos casos, reverem se realmente há necessidade do uso de medicações. Estas, apesar de eficazes, podem gerar dependência química, psicológica e deixar os usuários mais sonolentos durante o dia, interferindo, inclusive, na realização das atividades diárias.

Nosso estudo indicou que $69 \%$ dos participantes tinham hipertensão arterial; $61 \%$, problemas na coluna; e $46 \%$, osteoporose, sendo essas as patologias mais referidas no questionário. A presença dessas doenças, muitas vezes, pode limitar a vida social do idoso, comprometendo a sua qualidade de vida. Pereira et al. (2006) realizaram um estudo com uma grande amostra de pessoas com mais de 60 anos e verifica- 
ram que os fatores físicos foram os que mais tiveram relação com a qualidade de vida, seguidos de questões ambientais e psicológicas.

Mais especificamente em relação aos hábitos de vida dos idosos, observou-se que $31 \%$ assistiam muito à televisão, $38 \%$ escutavam muito rádio, $46 \%$ faziam pouca leitura e $61 \%$ nunca haviam utilizado o computador nem a internet. Esses dados indicam que, antes de começar a frequentar a oficina de memória, uma quantidade significativa dessas pessoas dedicava grande parte do seu tempo a atividades restritas ao âmbito doméstico, como assistir televisão e escutar rádio. Em contrapartida, poucos idosos tinham o hábito da leitura, atividade que tem sido mencionada como um dos fatores protetores para o aparecimento ou agravamento das demências. (IZQUIERDO, 2011).

\section{Segundo momento}

O segundo momento partiu da ideia de que o acesso à memória tem na narrativa uma de suas estratégias privilegiadas. Nesses termos, planejou-se uma série de atividades em que os participantes pudessem, de alguma forma, acionar o que se entende por memórias remotas, assumindo, então, o papel de narradores de sua própria história. Para tanto, foram utilizados alguns gatilhos evocativos, ou seja, estímulos para as lembranças, tais como: cantigas de roda, imagens de época, expressões populares, levantamento de eventos passados, entre outros.

A memória é o combustível da autobiografia, a qual, por sua vez, consiste no processo de trabalho em que o indivíduo seleciona, consciente ou inconscientemente, os eventos que tem como fundamentais em sua trajetória. Nesse exercício, após o estímulo, solicitou-se que os participantes "puxassem" pela memória e tentassem registrar, por escrito e/ou oralmente, o que lhes vinha à mente sobre o passado remoto diante daquele tema apresentado. Levando em consideração as diversas falhas a que as memórias estão sujeitas (SCHACTER, 2003), partiu-se do princípio de que o relatado não correspondia exatamente ao que fora vivenciado no passado, mas era resultado de muitos filtros, distratores e condicionantes a que qualquer processo de memória de longa duração está sujeito.

São recorrentes na experiência da memória os marcadores de vivências sociais, e as narrativas deste estudo estão repletas deles: o grande amor, o nascimento dos filhos, o mundo dos adultos, a casa da infância, uma viagem, a escola, o ambiente de trabalho, apenas para citar alguns.

Uma coisa que não saía da minha cabeça quando criança era de que as pessoas com vinte anos estavam velhas. Quando via meus pais conversando, que eles nunca deixavam ouvir, eu ficava imaginando que tanto assunto importante que gostaria de saber. (Relato de participante da oficina no caderno de autobiografia).

Os lugares e eventos resgatados pela memória estavam, por sua vez, repletos de pessoas, ações e artefatos: o primeiro beijo, o berço, o luto, o quintal, os avós, o carro, a boneca, entre outros. 
Sou da época em que o casal não ficava sozinho, estávamos sempre na companhia de mais de uma pessoa. Me lembro do dia em que saímos com a minha mãe e encontramos com uma conhecida. Enquanto elas conversavam, conseguimos trocar um beijo rapidinho. Hoje, lembro disso e acho muito engraçado. (Relato de participante da oficina no caderno de autobiografia).

Nesse processo, em alguns momentos, também foi possível perceber o bloqueio de certos participantes em construir essas narrativas e registrá-las no caderno de memórias. Porém, quando um colega dava um depoimento sobre a sua experiência de infância, não raro, os que diziam estar bloqueados demonstravam sentir uma melhora em suas evocações e passavam a registrar as lembranças, destacando, assim, o papel da sociabilidade que advém do diálogo entre os participantes.

Se o diálogo é um fator de integração, o ato de lembrar é para o idoso uma porta aberta para se avaliar, comparativamente, os aspectos qualitativos das experiências do passado em relação às do presente. Em seus relatos autobiográficos, os participantes, num primeiro momento, tenderam a afirmar que no passado foram mais felizes. Contudo, no decorrer das narrativas, foi possível perceber que essa tendência a imaginar uma idade de ouro não se sustentava, tendo em vista que vários problemas também eram trazidos à tona: a escassez material, a falta de liberdade, a assimetria de poder na relação com os adultos, as incertezas em relação ao futuro, entre outros.

\section{Terceiro momento}

Após um ano de realização da oficina de memória, procedeu-se a uma nova entrevista semiestruturada, com o intuito de verificar se o trabalho foi útil para esclarecer os frequentadores a respeito do processo de envelhecimento e das mudanças cognitivas, especialmente da memória, decorrentes dessa fase da vida. Por meio da entrevista, verificou-se que, após frequentarem a oficina de memória, uma série de atividades passou a ser realizada pelos idosos, dentre as quais, destacam-se: o aumento da frequência de leitura, o número de vezes que saem de casa, a quantidade de amizades feitas e a realização das atividades cognitivas. Esses novos hábitos foram percebidos com grande satisfação por toda a equipe executora da oficina, pois, em comparação ao momento inicial, ficam evidentes os ganhos sociais, podendo refletir em uma vida mais saudável e prazerosa, ao oportunizar uma maior interação social, a prática da leitura e o estabelecimento de amizades.

Uma das preocupações iniciais no momento de sua montagem foi que a oficina de memória se constituísse num espaço útil para socialização, trocas de experiências e transmissão de conhecimento. Também, teve-se o cuidado de mencionar que as falhas de memória fazem parte do envelhecimento saudável; ou seja, os participantes foram informados de que o fato de ocasionalmente se esquecerem de algo não é indicativo de demência. Na entrevista, questionados quanto ao seu conhecimento sobre a doença de Alzheimer, os idosos citaram como principais sintomas o esquecimen- 
to (inclusive de nomes), a alteração de comportamento e a perda da orientação. Com suas respostas, os participantes demonstraram ter construído um conhecimento adequado sobre o tema. Nesses termos, a oficina constituiu-se como um espaço útil para oferecer a conceituação correta e desfazer alguns mitos inicialmente relatados pelos idosos, como a crença de que qualquer esquecimento já poderia ser classificado como demência.

Quando questionados sobre os sentimentos e pensamentos presentes no momento em que se esquecem de algo, cinco idosos disseram considerar isso normal, três admitiram ficar com medo de desenvolver demência e dois relataram "puxar pela memória". Observa-se que, a despeito do aprendizado construído ao longo do curso sobre as características das demências, uma parcela de idosos ainda tem receio de desenvolvê-las, enquanto outros passaram a encarar os esquecimentos como algo corriqueiro e até esperado para a idade. Outro aspecto a se considerar é o fato de os participantes terem relatado "puxar pela memória" quando se esquecem de algo, de modo a indicar que estão utilizando na sua prática diária as diversas estratégias cognitivas que foram ensinadas e trabalhadas na oficina de memória ao longo do ano, tais como: caderno de anotações, associações de palavras com imagens e contextualização de situações vividas.

A respeito da capacidade ou não de realizar as tarefas do dia a dia, oito participantes referiram ainda ser capazes de executar a maioria delas. No caso dos idosos com limitação para realizar algumas atividades, as principais queixas remetem a dores e a lentidão, consequência da presença de inúmeras doenças, como osteoporose e problemas na coluna, citadas no questionário inicial da oficina.

No que diz respeito às atividades realizadas em sua rotina, $50 \%$ dos idosos entrevistados disseram que, sozinhos, apanham ônibus, pagam as contas, vão ao supermercado ou à padaria, contratam serviços externos (como pedreiros ou encanadores, por exemplo) e saem para passear.

Quando lhes foi solicitado que comparassem a sua memória atual com a de outras pessoas de idade semelhante, cinco idosos a consideraram razoável; um, ruim; e outros cinco a avaliaram como normal ou ótima. Em estudo desenvolvido por Almeida (1998), identificou-se que $59,1 \%$ dos 220 idosos avaliados queixavam-se de problemas com a memória e que os idosos possuidores de mais queixas apresentaram, com maior frequência, sintomas de depressão ou de ansiedade. Além disso, o autor concluiu que as queixas de memória da população da terceira idade estiveram pouco correlacionadas com um diagnóstico real de demência, salientando que as queixas subjetivas não são o principal indicativo da ocorrência dessa patologia.

Questionados se há alguma tarefa que gostariam de executar, mas que não conseguem mais em razão de sua memória, cinco idosos afirmaram que continuam realizando as mesmas atividades de sempre; contudo, três admitiram que, atualmente, têm dificuldade de recordar o aniversário de pessoas próximas. Ressalta-se que os esquecimentos apontados 
pelos participantes, somados aos demais dados da entrevista e à observação feita durante as tarefas, levam a crer que a queixa relatada configura tão somente traços benignos da terceira idade. De acordo com Charchat-Firchman et al. (2003), esses esquecimentos são característicos de grande parte dos idosos que vivenciam um envelhecimento saudável, uma vez que nessa etapa da vida uma série de transformações cerebrais se processa, podendo ter como consequência falhas de memória, as quais ocorrem ocasionalmente e não alteram de maneira significativa as atividades de vida diária do idoso, nem suas funções cognitivas.

Sete idosos expuseram que a oficina mudou significativamente o conhecimento que tinham a respeito da memória. Esse dado permite concluir que a oficina cumpriu o seu papel, ao transmitir para os seus participantes conhecimento em relação à terceira idade e à demência. Destaca-se que, para elaborar as palestras voltadas a esse público, um conjunto de aspectos foi considerado: duração deu-se prioridade a falas mais curtas, para não causar fadiga; utilização de recursos visuais e sonoros - grande parte das palestras foi apresentada em data-show, com a utilização de imagens ou músicas, visando a favorecer a memorização da temática trabalhada; e linguagem acessível - os temas e os termos empregados nas palestras, sempre que possível, foram adaptados aos participantes, a fim de otimizar o aprendizado.

Em relação às dicas que os idosos teriam para melhorar a memória, cinco recomendaram a realização de palavras cruzadas, oito apontaram o hábito da leitura e três, a participação na oficina de memória. Assim, as respostas dadas pelos participantes demonstram que eles têm buscado estratégias úteis para otimizar os processos de memória. Yassuda et al. (2006) verificaram que, após quatro sessões apenas nas quais eram ensinadas estratégias cognitivas aos idosos, esses as empregaram mais intensamente na realização da testagem neuropsicológica, o que vem ao encontro de nossos achados.

\section{Conclusão}

A oficina de memória teve como intuito primordial realmente representar um projeto de extensão no sentido mais amplo da palavra. Seu objetivo, portanto, foi que os participantes pudessem adquirir os conhecimentos relativos aos processos da memória e das particularidades da terceira idade, capacitando-se para utilizá-los em sua vida prática e para atuar como agentes multiplicadores do conhecimento adquirido, na sua comunidade, com seus vizinhos, amigos ou parentes.

Outro objetivo, igualmente relevante, da oficina foi o de constituir-se como espaço de socialização desses idosos, oportunizando, ainda, a realização de atividades lúdicas por meio de jogos. Fundamentada em três pilares, conhecimento, socialização e ludicidade, uma gama de transformações por parte dos participantes pôde ser observada ao longo do ano em que se desenvolveu o trabalho. Algumas dessas mudanças puderam ser expostas quantitativa e/ou qualitativamente neste estudo; outras, 
porém, somente podem ser medidas pelos sorrisos testemunhados, pelos abraços carinhosos entre os participantes e pelos agradecimentos afetuosos dos idosos.

Memory workshop for seniors: a space for knowledge, socialization and recreational

\section{Abstract}

Each step of functioning must be understood and lived according to their particularities and considered from a range of aspects of personal, social and cognitive own. In order to provide the elderly a better understanding of normal aging and dementia, workshops have been conducted in this population. Our study analyzed three times (beginning, middle and end) of a memory workshop for seniors held throughout 2011, using questionnaires, interviews and reports. At the beginning of the project was carried out semi-structured interview with the issues related to lifestyle and cognitive aspects. At the end of the first half of 2011, there was the second time that consisted of the construction of an autobiography, so that we could stimulate in evoking memories considered the most remote and they could be expressed in a memory book. After a year of holding the workshop memory perform a new semi-structured interview in order to verify that the workshop was useful for clarifying about the aging process and cognitive changes, especially memory. It should be noted that the ultimate aim of our workshop was memory be based on three pillars: knowledge, socialization, and playfulness. In addition, we aimed that the workshop was really an extension project in the broadest sense of the word, ie the participants to acquire knowledge regarding the processes of memory and the particularities of the elderly and act as multipliers of knowledge acquired.

Keywords: Memory. Elderly. Socialization. Playful.

\section{Referências}

ALMEIDA, M. H. M.; BEGER, M. L. M.; WATANABLE, H. A. W. Oficina de memória para idosos: estratégia para promoção da saúde. Interface - Comunicação, Saúde, Educação, Botucatu, v. 11, n. 22, p. 271-280, 2007.

ALMEIDA, O. P. Miniexame do estado mental e o diagnóstico de demência no Brasil. Arquivo de Neuro-Psiquiatria, São Paulo, v. 56, n. 3-B, p. 605-612, 1998.

ARRUDA, I. E. A. Universidade da terceira idade: análise de um programa pioneiro. Revista Brasileira de Ciências do Envelhecimento Humano, Passo Fundo, v. 7, n. 1, p. 84-96, 2010.

CHARCHAT-FICHMAN, H. et al. Declínio da capacidade cognitiva durante o envelhecimento. Revista Brasileira de Psiquiatria, São Paulo, v. 27, n. 12, p. 79-82, 2005.

FELICIANO, A. B.; MORAES, A. S.; FREITAS, I. C. M. O perfil do idoso de baixa renda no Município de São Carlos, São Paulo, Brasil: um estudo epidemiológico. Caderno de Saúde Pública, Rio de Janeiro, v. 20, n. 6, p. 1575-1585, 2004.

GARRIDO, R.; MENEZES, P. R. O Brasil está envelhecendo: boas e más notícias por uma perspectiva epidemiológica. Revista Brasileira de Psiquiatria, São Paulo, v. 24, n. Supl. I, p. 3-6, 2002.

GEIB, L. T. C. et al. Sono e envelhecimento. Revista de Psiquiatria, Rio Grande do Sul, v. 25, n. 3, p. 453-465, 2003.

GUERRA, A. C. L. C.; CALDAS, C. P. Dificuldades e recompensas no processo de envelhecimento: a percepção do sujeito idoso. Ciência \& Saúde Coletiva, Rio de Janeiro, v. 15, n. 6, p. 2931-2940, 2010.

HAMDAM, A. C.; BUENO, O. F. A. Relações entre controle executivo e memória episódica verbal no comprometimento cognitivo leve e na demência tipo Alzheimer. Estudos de Psicologia, Natal, v. 10, n. 1, p. 63-71, 2005. 
IZQUIERDO, I. Questões sobre memória. Rio Grande do Sul: Ed. Unisinos, 2004.

med, 2011.

Memória. Rio Grande do Sul: Art-

KALACHE, A.; VERAS, R. P.; RAMOS, L. R. O envelhecimento da população mundial. Um desafio novo. Revista de Saúde Pública, São Paulo, v. 21, n. 3, p. 200-210, 1987.

LENT, R. Neurociência da mente e do comportamento. Rio de Janeiro: Guanabara Koogan, 2008.

LIMA-COSTA, M. F. A escolaridade afeta, igualmente, comportamentos prejudiciais à saúde de idosos e adultos mais jovens? Inquérito de Saúde da Região Metropolitana de Belo Horizonte, Minas Gerais, Brasil. Epidemiologia e Serviços de Saúde, Brasília, v. 13, n. 4, p. 201-208, 2004.

LUZARDO, A. R.; GORINI, M. I. P. C.; SILVA, A. P. S. S. Características de idosos com doença de Alzheimer e seus cuidadores: uma série de casos em um serviço de neurogeriatria. Texto Contexto Enfermagem, Florianópolis, v. 15, n. 4, p. 587-594, 2006.

MENDES, M. R. S. S. B. M. et al. A situação social do idoso no Brasil: uma breve consideração. Acta Paulista de Enfermagem, São Paulo, v. 18, n. 4, p. 422-426, 2005.

PARAHYBA, M. I.; VERAS, R.; MELZER, D. Incapacidade funcional entre as mulheres idosas no Brasil. Revista de Saúde Pública. São Paulo, v. 39, n. 3, p. 383-391, 2005.

PEREIRA, R. J. Contribuição dos domínios físico, social, psicológico e ambiental para a qualidade de vida global de idosos. Revista de Psiquiatria, Rio Grande do Sul, v. 28, n. 1, p. 27-38, 2006.

PINTO, A. L. F. Memória: um desafio à autonomia do idoso. Família Saúde e Desenvolvimento, Curitiba, v. 1, n. 1, p. 39-48, 1999.

SCHATER. D. L. Os sete pecados da memória. Rio de Janeiro: Rocco, 2003.

SILVA, C. A.; CARVALHO, L. S.; SANTOS, A. C. P. O. Vivendo após a morte de amigos: história oral de idosos. Texto e Contexto
Enfermagem, Florianópolis, v. 16, n. 1, p. 97-104, 2007.

SOARES, E. et al. Projeto Memória e Envelhecimento: capacitando profissionais e aprimorando aspectos cognitivos em idosos institucionalizados. Revista Brasileira de Ciências do Envelhecimento Humano, Passo Fundo, v. 7, n. 1, p. 62-73, 2010.

SOUZA, J. C.; REIMÃO, R. Epidemiologia da insônia. Psicologia em Estudo, Maringá, v. 9, n. 1, p. 3-7, 2004.

SOUZA, J. N.; CHAVES, E. C. O efeito do exercício de estimulação da memória em idosos saudáveis. Revista da Escola de Enfermagem da USP, São Paulo, v. 39, n. 1, p. 13-19, 2005.

VERAS, R. P.; RAMOS, L. R.; KALACHE, A. Crescimento da população idosa no Brasil: transformações e consequências. Revista de Saúde Pública, São Paulo, v. 21, n. 3, p. 225-233, 1987.

YASSUDA, M. S. et al. Treino de memória no Idoso Saudável: Benefícios e Mecanismos. Psicologia: Reflexão e Crítica, Porto Alegre, v. 19, n. 3, p. 470-481, 2006. 